JOCM

11,3

260

\title{
Multiple personalities: the case of business process reengineering
}

\author{
Hans Pruijt \\ Erasmus U niversity Rotterdam, Rotterdam, T he Netherlands
}

\section{Introduction}

Making sense of the debate on business process reengineering (BPR) is a daunting task. One is confronted with a wide variety of contradictory interpretations. Some see it as a break with Taylorism (Davenport and Short, 1990), others see it as a direct continuation of T aylorism (T inaikar et al., 1995). Chief proponents see it as something very different from continuous improvement (Hammer and Champy, 1994, p. 49). Others refuse to see a sharp distinction between BPR and continuous improvement (W inslow, 1996). On the one hand we learn that BPR is a self-conscious A merican way of outsmarting rather than imitating the Japanese (Grint, 1997, p. 45). On the other hand, Japanese companies such as Toshiba (television production in the UK) appear among best practice examples of BPR (Oram and Wellins, 1995). Some see a clean slate approach as essential, others maintain that analyzing and modeling existing processes is worthwhile as part of BPR (Jacobson et al., 1994). There are also authors who treat BPR in the context of management fads, which would basically mean that BPR means little at all.

Finally, the core BPR literature is not free from internal contradictions.

The starting point in this paper for dealing with these differences and inconsistencies is: accepting that BPR has more than one identity. In doing so, the paper deconstructs BPR into four identities.

\section{Identity one: BPR as management fad (BPR-F)}

$M$ anagement fads are the products of the management consultancy and management literature industry. One would expect a management fad to be launched as something new, to be promoted by gurus, to be mostly inconsequential when applied and to be more a matter of presentation than of content. BPR seems to qualify well as a management fad if one takes the pointer from super-guru Peter Drucker who says on the cover of Reengineering the Corporation: "Reengineering is new, and it has to be done." Hammer and Champy themselves take care of the criterion of predominant failure. They estimate that 50-70 per cent of all BPR efforts fail (Hammer and Champy, 1994,

Journal of Organizational Change Management, Vol. 11 No. 3, 1998, pp. 260-268, ( ) M CB University Press, 0953-4814
The author wishes to thank M art-Jan de Jong, B ram Steijn, Sandra Groeneveld, three anony mous reviewers and the editors of this special issue for their stimulating comments on earlier drafts of this paper. 
p. 200). The lightweight character of the BPR notion shows in the ease with which Hammer and Champy (1994) relabeled the redesign of the parts acquisition process, performed at Ford under the TQM (total quality management) label, as a core case of BPR. T homas Davenport, one of the reengineering pioneers, seems to have come to the conclusion that BPR has developed into a fad. He stated: "A $s$ is al ways the case with any fad, there was a kernel of truth in reengineering. Over time that truth got lost." (quoted in Mumford, 1996. p. 328).

Since BPR-F is relatively devoid of theory (M umford and Hendricks, 1997), this allows many to project their own interests and concerns into it (Scarbrough, 1996). BPR-F is a fad with a life cycle like any other. Judged from its exposure in the trade press, BPR-F may be slightly over the hill (Mumford and Hendricks, 1997; Simon, 1996).

\section{Identity two: BPR as a neo-Taylorist movement (BPR-N)}

Some of the ideas in BPR are relatively clear and straightforward. The most salient feature is the aggressive managerial mindset that it entails. A famous quote from M ichael Hammer: "It's basically taking an axe and a machine gun to your existing organization" (Computerworld, 1994). There is a loud argument for a clean-slate approach. A Iso clear is the idea of integrating business processes across functional borders: the attack on "functional silos".

However, in terms of the classical debate on work processes, i.e. the debate which focuses on the division of labor and on skill and control, BPR is a loose concept. On the one hand, BPR seems to be an attack on Taylorism. Purportedly "reengineering rejects the assumptions inherent in A dam Smith's industrial paradigm - the division of labor, economies of scale" (Hammer and Champy, 1994, p. 49). Hammer and Champy (1994, p. 53) claim that: "Instead of separating decision making from real work, decision making becomes part of the work. Workers themselves now do that portion of a job that, formerly, managers produced." They say that work becomes "more rewarding since people's jobs have a greater component of growth and learning" (Hammer and Champy, 1994, p. 69). A mplifying this point, we are told that "Companies that have reengineered don't want employees who can follow rules; they want people who will make up their own rules" (Hammer and Champy, 1994, p. 70).

On the other hand, a different picture emerges when we look into the solutions that Hammer and Champy present. In this area we see an unproblematic acceptance of Tayloristic solutions. Examples are the use of knowledge-based information systems to replace "highly trained" specialists with (teams of) "generalists" (Hammer and Champy, 1994, p. 38), "triage" (i.e. splitting off difficult cases and assigning these to specialists) or in a decentralized organization, using centralized computer controls.

Hammer and Champy do not acknowledge this internal contradiction or paradox. This might be for reasons of marketing: the managerial masses 
JOCM

11,3

262

probably do not wish to be burdened with complex questions. The contradiction may also be resolved by labeling the concern for human resource management a "veneer" (Willmott, 1995a) that is covering a Tayloristic reality. A teast one study came to the conclusion that: "Despite its stated departure from Taylorism, its ends are the same as many previous fads - the development (and imposition) of organizational control systems to secure compliance" (Blair et al., 1997, p. 20). A nother study consisting of a content analysis of 248 articles on BPR concluded: "BPR is a purely top-down approach to restructuring organizations in order to increase efficiency on the basis of technical design criteria. In this sense the principles of BPR are no different from the principles of scientific management espoused by Frederick Taylor in the early part of this century", (T inaikar et al., 1995, p. 109).

Loh came to the following verdict:

The assumption is that re-engineering is done for one reason only and that is process redesign. If this assumption is carried to its furthest, the ideal company would be staffed by nothing but robots. M ost self-styled re-engineering gurus have done nothing to contradict these assumptions. Robots work productively; people will always cause problems. Re-engineering has entered the business world more or less on the industrial engineering side of the management science conflict. Carried to its extreme, it can be made to define every motion of the work to be done. Re-engineering is certainly capable of setting up a very detailed work process, completely ignoring the abilities of people as well as totally eliminating any vestige of ingenuity on their part (Loh, 1995, p. 105).

A nother possible way of dealing with the contradiction is to accept that BPR might, albeit in some cases, indeed lead to outcomes that deviate from Taylorism. In BPR as defined by Hammer and Champy, however, any movement away from Taylorism is a by-product of the streamlining process, not a condition for successful change. Since on the level of ideas, BPR deviates from Taylorism, and further because incidental non-Tayloristic outcomes are possible, it would be confusing to simply write off BPR as Tayloristic. Instead, a more appropriate label would be neo-T aylorism. Neo-T ayloristic management approaches have the following characteristics:

(1) a top-down streamlining of operations;

(2) unproblematic acceptance of typical Taylorist solutions;

(3) asserting that the outcome for workers is an upgraded work content.

BPR is not alone in the neo-Tayloristic category. Lean production exhibits the same characteristics (see Pruijt, 1997, pp. 8-10).

BPR-F largely replaced T QM (total quality management) as a fad. If we follow the thinking of Hammer and Champy $(1994$, p. 49) this is because T QM/kaizen is incapable of delivering breakthroughs. Counter-arguments to this claim are that companies like Toyota achieved dramatic results with continuous improvement on a massive scale and that Hammer and Champy themselves use relabeled TQM as an example of outstanding BPR (Winslow, 1996). Winslow suspects that opportunistic motives lead some to trumpet BPR over TQM: "Those people who seek to gain the most from new 
concepts often find ways to degrade what has been done before" (Winslow, 1996, p. 7).

However, a key difference between TQM and BPR-N is that TQM involves giving some control to subordinates, while BPR does not. Managers who are unhappy with the participative aspect of TQM are swinging to a more authoritarian position while embracing BPR (Grint, 1997, p. 49). As an interesting analysis in Wired concluded: "Corporate leaders tend to like Hammer's approach because they can get rid of the cumbersome, bureaucratic chain of command,

Multiple personalities without ceding control. Instead of giving orders, they can 'program' the corporation" (Kleiner, 1995). Thus, BPR-N helped BPR-F to the top.

\section{Identity three: BPR as a euphemism for downsizing (BPR-D)}

BPR has become inextricably linked to downsizing, getting known as "big people reduction" (US) and "bastards planning redundancies" (UK). BPR-D has its outright advocates, such as Lyle M. Spencer who wrote a book with the unmistakable title Reengineering Human Resources: A chieving Radical Increases in Service Quality - with 50 percent to 90 percent Cost and Head Count Reductions. His definition of BPR: "Reengineering is ... creative destruction - the breaking down of old ways to free resources for new and higher uses ... reengineers are to bloated, inefficient organizations what flies are to garbage: they break the mess down into clean elements, freeing underutilized resources (primarily people and capital) to be recombined to create higher value-added products and services" (Spencer, 1995, p. 33).

In interviews, Hammer and Champy have played innocent but in an ambiguous way. They have said that reengineering was not downsizing, but if downsizing was the result of reengineering this had to be accepted (Mumford, 1996; M umford and Hendricks, 1997).

However, in the reengineering stories that Hammer and Champy present as models in their Reengineering the Corporation: A M anifesto for a Business Revolution, there is a lot of downsizing. One of these stories deals with Bell A tlantic's reengineering of the process of linking customers with their chosen long distance carriers. Step one is reengineering this into an integrated process handled by case teams. These teams are to be driven by commitment. The next step is replacing the case team with one caseworker, assisted by new technology. The final step planned is to install technology that enables the customers to do the work by themselves. Labor cost is expected to fall by 93 percent (Hammer and Champy, 1994, pp. 195-7). The link between BPR-N and BPR-D is moretight than Hammer and Champy would haveit. Successfully applied Taylorism makes workers exchangeable. Therefore, BPR-N helps BPR-D.

\section{Identity four: BPR as a non-normative label for business process oriented change efforts (BPR-P)}

It may be tempting to think of BPR as the application of the ideas of the reengineering gurus. This would imply that something could be BPR only 
JOCM

11,3

264

when it was started under the label of BPR. However, this is not the case. Business process oriented change efforts were going on before the term BPR was coined. Of necessity, Hammer and Champy themselves substantiated their ideas by picking up stories dating from times before the BPR label existed, thereby engineering reengineering into history. They are quick to point out that they did not invent BPR, at most they just discovered it (Hammer and Champy, 1994, p. 220). The other early BPR promoters also constructed their vision using cases in which the actors did not think of themselves as applying BPR (Davenport, 1993; Davenport and Short, 1990).

This means that the BPR field remains open for contributors who, for example, accept Hammer and Champy's (1994, p. 32) definition ("the fundamental rethinking and radical redesign of business processes to achieve dramatic improvements in critical, contemporary measures of performance, such as cost, quality, service and speed") but who are not prepared to swallow the neo-T ayloristic bias. A fter all, there is nothing inherently Tayloristic in Hammer and Champy's definition of BPR itself. Moreover, not all BPR gurus display the same degree of neo-Taylorist bias as Hammer and Champy do. This becomes clear when we apply the three criteria of neo-T aylorism (top-down streamlining of operations, unproblematic acceptance of typical Taylorist solutions, asserting that the outcome for workers is an upgraded work content) to the work of Thomas Davenport (and co-authors).

The criterion of the top-down streamlining of operations seems to apply. For example, Davenport sees his thinking as "new industrial engineering" (Davenport and Short, 1990) and acknowledges its roots in Taylorism (Davenport, 1993). How ever, Davenport does not unproblematically accept typical Taylorist solutions. Neither does he assert that the outcome for workers is an upgraded work content. He concedes that IT -enabled process innovation supports both empowerment and control and states "We are not enthusiastic about control-oriented cultures (we wouldn't want to work in such environments), but they are possible and sometimes necessary" (Davenport, 1993, p. 96).

In his view, the four most likely objectives of business process redesign are:

(1) cost reduction;

(2) time reduction;

(3) output quality; or

(4) "quality of worklife (QW L)/learning/empowerment".

Referring to the goal of QW L/learning/empowerment he remarks: "Of course, it is rarely possible to optimize all objectives simultaneously, and in most forms, the strongest pressures are to produce tangible benefits. Yet managers who ignore this dimension risk failure of redesigned processes for organizational and motivational factors" (Davenport and Short, 1990, pp. 14-5). 
Throughout Davenport's work there are hints of organizational choice, such as in the following statement: "... process innovation as we have defined it is by no means a simple extension of Taylorism. The human contribution to work is to be celebrated and optimized rather than eliminated. Innovative process designs can leave room for creativity and worker autonomy" (Davenport, 1993, p. 316). A lthough Davenport criticizes sociotechnical systems design, he implicitly grants it a role in the future by suggesting that it can be improved: "W hat process innovation can bring to sociotechnical work design is the importance of radical improvement in results and the measurement and improvement focus of process thinking" (Davenport, 1993, p. 317). Nevertheless, Davenport's approach does not redress the neo-Taylorist bias (BPR-N). The Tayloristic side of the story is bolstered with concrete examples complete with metrics. The non-Tayloristic side remains relatively vague and underdeveloped.

But is it realistic to expect that many researchers and consultants will jump to fill this gap? It is possible that BPR-F, because of its strong claim of performance and its (weak) claim of quality of working life, will steal the thunder of rival non-Taylorist approaches. This could motivate nonTayloristically minded consultants and researchers to hop on the bandwagon while hoping to influence its course.

A $n$ example of this is a reinterpretation of the famous 1949 sociotechnical UK mining case as BPR (M umford and Beekman, 1995, pp. 36-42).

On the other hand, because of BPR-N, individuals who are highly critical of Taylorism will not feel any attraction to BPR. M oreover, BPR-D makes workers afraid of BPR. A pparently, a fitting metaphor in this respect is workers as poultry. In the literature, a middle manager of a pharmaceutical company is quoted as saying: "I'm like the turkey who survived Thanksgiving. It's nice I survived, but Christmas is coming" (Johansen and Swigart, 1994, p. x). Unlike BPR-N, non-T ayloristic change is dependent on worker participation. One researcher rhetorically asked: "Will the turkeys vote for Christmas?" (Willmott, 1995b). T his means that one might be ill advised to launch a non-T ayloristic change program under the label of BPR. A nd the implication is that nonTayloristic cases of BPR-P, while existing, are not very likely to be presented as "BPR".

This is a paradox: for a full appreciation of BPR-P, that is for gauging the full range of organizational choice involved, one needs to look at work that does not come under the label of BPR. Non-Tayloristic cases that can be viewed as BPR-P exist, and can be found documented with achievements and pitfalls (Pruijt, 1997).

The value of a full appreciation of BPR-P is twofold: it is necessary for maintaining and improving the quality of working life, but it also gives access to the options for increasing organizational adaptability and mobilization of intelligence and knowledge. BPR-D and BPR-N may lead to improvements in terms of cost and speed. However, in the areas of adaptability and mobilization 
JOCM

11,3

266

of intelligence and knowledge, BPR-D and BPR-N are likely to have adverse effects (Davenport and Prusak, 1998).

Some of the failures in BPR can be attributed to a neo-Tayloristic bias. A case in point is United Parcel Service. It reengineered its delivery service, speeding it up and increasing supervision. How ever:

Soon, the UPS found that customers were not so much concerned about the promptness of delivery at 10:30 am as they were about talking to the drivers about the customer services available from UPS. By trying to chase the delivery schedule, UPS seemed to have lost its major advertising asset viz., drivers, and ended up having poor labor relations in the bargain. Since then, UPS has increased the number of drivers, given them more time for delivering parcels to customers and reduced the supervision; delegating to drivers the ownership of work (A runachalam and Subrahmanian, 1995).

(In the 1997 UPS strike, working conditions were not an issue.)

\section{The multiple identities get in one another's way}

As we have seen, BPR-N injects a Taylorist bias in BPR-P. This effect is selfreinforcing: because of $B P R-N$, few non-Tayloristically minded researchers and consultants feel compelled to contribute ideas to the BPR-P arena. BPR-D causes fear, which in turn leads to low trust relations in the workplace. This makes non-Tayloristic options in BPR-P less likely, and increases the transaction costs in all forms of BPR-P. Since non-Tayloristic change is by definition dependent on worker participation, starting non-Tayloristic change projects under the label of "BPR" seems not advisable. This can explain why non-Tayloristic cases in the BPR literature tend to be relabeled cases that originally belonged to other traditions. But many non-Tayloristic BPR-P cases will paradoxically remain outside of the BPR literature.

$B P R-N$ contributes to failures in BPR-P. Because of the ideological influence of BPR-N on BPR-P, there is not more than a weak correction mechanism. Therefore, frustration will turn against the BPR concept in general.

BPR-N helped BPR-F to the top. BPR-F generates interest, but, like any fashion, it will burn out. Meanwhile BPR-D, which is boosted by BPR-N, is already de-legitimizing BPR-F. Nevertheless, the underlying issues - the dilemmas of organizational choice in process change - will always bethere, and keep our field lively and interesting.

A few implications for future research can be drawn. It is important to make a distinction between, on the one hand, change projects that live under the label of $B P R$ right from their inception, and on the other hand, cases that were retrospectively labeled as BPR.

From the discussion of the interplay between the multiple personalities one can derive the following hypothesis: increasingly, change projects that are started under the label of BPR will show a Taylorist bias. A ttempting to test this hypothesis would require careful observation at the shopfloor level. Changes in job design must be assessed in terms of skill and control. 


\section{References}

A runachalam, V. and Subrahmanian, E. (1995), Business Process A nalysis - A Letter from A merica, Carnegie M ellon University, Pittsburgh, PA, http://bprc.warwick.ac.uk/aruncontents-0.html.

Blair, H. et al. (1997), A Pernicious Panacea. A Critical Evaluation of Business Reengineering, paper presented at the 15th A nnual International Labour Process Conference, University of Edinburgh, March 25.

Computerworld (1994), 24 January.

Davenport, T.H. (1993), Process Innovation: Reengineering Work through Information Technology, Harvard Business School Press, Boston, MA.

Davenport, T.H. and Prusak, L. (1998), Working K nowledge How Organizations Manage What They K now, Harvard Business School Press, Boston, MA.

Davenport, T.H. and Short, J.E . (1990), "T he new industrial engineering: information technology and business process redesign", Sloan M anagement Review, Summer, pp. 11-26.

Grint, K. (1997), Fuzzy M anagement. Contemporary Ideas and Practices at Work, Oxford University Press, Oxford.

Hammer, M. and Champy, J. (1994), Reengineering the Corporation. A Manifesto for Business Revolution, HarperCollins, New York, NY.

Jacobson, I. et al. (1994), T he Object A dvantage Business Process Reengineering with Object Technology, A ddison-Wesley, Reading.

Johansen, R. and Swigart, R. (1994), U psizing the Individual in the Downsized Organization: Managing in the Wake of Reengineering, Globalization, and Overwhelming Technological Change, A ddison-Wesley, Reading.

Kleiner, A . (1995), "T he battle for the soul of corporate A merica. Hammerism battles Demingism for how the corporation (or society) should be governed in the information age", W ired, http://wwww.wired.com/wired/3.08/features/reengineering.html.

Loh, M . (1995), Re-engineering at Work, Gower, A ldershot.

Mumford, E. (1996), "Risky ideas in the risk society", Journal of Information Technology, Vol. 11, pp. 321-31.

Mumford, E. and Beekman, G.J. (1995), Tools for Change and Progress : A Socio-Technical A pproach to Business Process Reengineering, CSG Publications, Leiden.

M umford, E . and Hendricks, R. (1997), Reengineering Rhetoric and Reality: The Rise and Fall of a M anagement Fashion, Warwick URL: http://bprc.warwick.ac.uk/rc-repb-6.html, ESRC Business Processes Resource Centre.

Oram, M. and Wellins, R.S. (1995), Re-engineering's M issing Ingredient: The Human Factor, Institute of Personnel and Development, London.

Pruijt, H. (1997), Job Design and Technology, Taylorism vs. Anti-Taylorism, Routledge, London, New York.

Scarbrough, H. (1996), Business Process Re-design: T heK nowledge Dimension, Warwick Business School, University of Warwick, http://bprc.warwick.ac.uk/rc-rep-8.html.

Simon, K.A . (1996), BPR - Sic Transit Gloria M undi or What Else Is New in Management?, Göteborg University, School of Economics \& Commercial Law, Department of Informatics, Göteborg.

Spencer, L.M.J. (1995), Reengineering Human Resources: A chieving Radical Increases in Service Quality - with $50 \%$ to $90 \%$ Cost and Head Count Reductions, Wiley, New York, NY. 
JOCM

11,3

268

T inaikar, R. et al. (1995), "Rethinking business process re-engineering: a social constructionist perspective", in Burke, G. and Peppard, J. (Eds), Examining Business Process Re-engineering: Current Perspectives and Research Directions, Kogan Page, London, pp. 107-16.

Willmott, H. (1995a), "T he odd couple? Re-engineering business processes; managing human relations", New Technology, Work and Employment. Vol. 10, pp. 89-98.

Willmott, H. (1995b), "W ill the turkeys vote for Christmas? The re-engineering of human resources", in Burke, G. and Peppard, J. (Eds), Examining Business Process Re-engineering: Current Perspectives and Research Directions, Kogan Page, London, pp. 306-15.

Winslow, W. (1996), Strategic Business T ransformation: A chieving Strategic Objectives through Business Reengineering, M cGraw-Hill, M aidenhead. 